\section{International Scientific Journal Theoretical \& Applied Science}

\author{
p-ISSN: 2308-4944 (print) e-ISSN: 2409-0085 (online) \\ Year: $2015 \quad$ Issue: 05 Volume: 25
}

Published: $30.05 .2015 \quad$ http://T-Science.org

SECTION 6. Metallurgy and energetics.
Yuri Andreevich Getmanovskij master student, depatment of Materials Science, technology of materials and heat treatment of metals Nizhny Novgorod State Technical University named after R.E. Alekseev (NNSTU), Russia getmanovskij@yandex.ru Mikhail Aleksandrovich Romashev master student, NNSTU, Russia

Evgeniy Sergeevich Beljaev Ph.D., Associate Professor, NNSTU, Russia

Sergey Victorovich Kostromin Ph.D., Associate Professor, NNSTU, Russia

Gennadiy Nikolaevich Gavrilov Doctor of Technical Sciences, Professor, NNSTU, Russia

\title{
RESEARCH INFLUENCE OF CONTACT HEAT TREATMENT ON THE STRUCTURE AND PROPERTIES OF STEEL H18N15
}

Abstract: The application of materials manufactured by powder metallurgy techniques in medicine. The effect of contact thermal heating on the submissions received. Held mechanical and microstructural studies of treated materials. The optimum heat treatment regime.

Key words: powder metallurgy, contact heat treatment.

Language: Russian

Citation: Getmanovskij YA, Romashev MA, Beljaev ES, Kostromin SV, Gavrilov GN (2015) RESEARCH INFLUENCE OF CONTACT HEAT TREATMENT ON THE STRUCTURE AND PROPERTIES OF STEEL H18N15. ISJ Theoretical \& Applied Science 05 (25): 84-87.

Soi: http://s-o-i.org/1.1/TAS*05(25)17 Doi: crossef http://dx.doi.org/10.15863/TAS.2015.05.25.17

\section{ИССЛЕДОВАНИЕ ВЛИЯНИЯ КОНТАКТНОЙ ТЕРМИЧЕСКОЙ ОБРАБОТКИ НА СТРУКТУРУ И СВОЙСТВА СТАЛИ Х18Н15}

Аннотация: Рассмотрено применение материалов, изготовленных методами порошковой металлургии в промышленности на примере стали Х18Н15. Изучено влияние контактного термического нагрева, на полученные материаль. Проведены механические и микроструктурные исследования обработанных материалов. Выбран оптимальный режим термической обработки.

Ключевые слова: порошковая металлургия, контактная термическая обработка.

Нержавеющая сталь является незаменимым материалом для изготовления обширного перечня промышленных и бытовых инструментов и оборудования. Развитие современных средств производства и применение инновационных технологий влечет за собой увеличение применения нержавеющей стали в различных отраслях машиностроения [1].

Контактный нагрев (контактная термообработка, КТО), основан на свойстве электрического тока выделять тепло при прохождении по проводнику. В качестве проводника используется сама нагреваемая заготовка. Она зажимается между контактами из красной меди, и по ней пропускается ток силой в 10 кА. При этом выделяется количество тепла, необходимое для нагревания заготовки до температуры аустенитного превращения.

Контактный нагрев имеет ряд достоинств, по сравнению с печным нагревом: небольшой расход электроэнергии, простота оборудования, быстрота и равномерность нагрева. Вследствие этого он широко применяется как для нагрева длинных заготовок постоянного сечения (L>>S) под штамповку на молотах и прессах, так и для нагрева части заготовки под местную деформацию, например гибку. Часть заготовки, зажатая в контактах, имеет температуру на 100 $150^{\circ}$ ниже температуры центральной части. Это исключает возможность применения контактного нагрева для изготовления изделий методами высадки[2]. 
В данной работе рассматривается Х18Н15, изготовленная методами порошковой металлургии (ПМ).

Сталь Х18Н15 применяется для производства порошка, используемого в произодстве проницаемых изделий и пористой прокатанной и спеченной ленты; листов пористых, предназначенных для изготовления фильтров тонкой фильтрации от механических примесей жидких и газообразных веществ: топлива Т-1, Т-2, ТС-1, Т-6; гидрожидкостей АМГ-10, 7-500-3, МГЕ-10А, МГЕ-АУ, МГЕАУП, МГЕ-4; масла типа РМ, ЛЗМ 36/1; газов воздуха, азота, кислорода, фреона, гелия, водорода и других газов и технических жидкостей, a также для изготовления пламягасителей, пористых охладителей. Порошок из стали Х18Н15 изготавливают методом совместного восстановления смеси оксидов металлов и металлических порошков гидридом кальция.

Исходный материал - лента нержавеющей стали марки ХІ8Н15, имеющая пористость после спекания $23 \%$. Она предназначена для изготовления фильтров тонкой очистки от механических примесей в интервале температур от -60 до $+250^{\circ} \mathrm{C}$ следующих жидких и газообразных веществ: топлива

Порошковая сталь была выбрана по причине того, что изделия, изготовленые по методу ПМ, за счет пористости имеют не удельную теплопроводность, ниже компактных материалов, что повышает эффективность контактного нагрева. Дополнительным положительным фактором является то, что при таком методе изготовления изделий снижается возникновения внутренних дефектов после термической обработки. Актуальность использования порошковой стали высока по причине того, что порошковые материалы находят все большее широкое применение в промышленности: изделия из них можно подвергать лазерной сварке, резке и прочим методам высокоэнергетическим методам термической обработки $[3,4]$.

В работе было исследовано влияние КТО на структуру и свойства стали Х18Н15. Режимы обработки указаны в таблице 1. Параметры установки: выходная мощность $\mathrm{W}=850 \mathrm{~B}$, при силе тока $\mathrm{I}=0,5$ кА, напряжение $\mathrm{U}=1,7$ В. Процесс КТО представлен на рисунке 1.

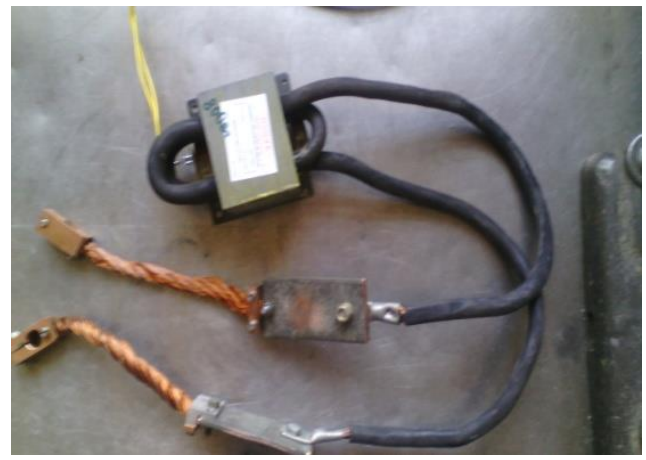

a)

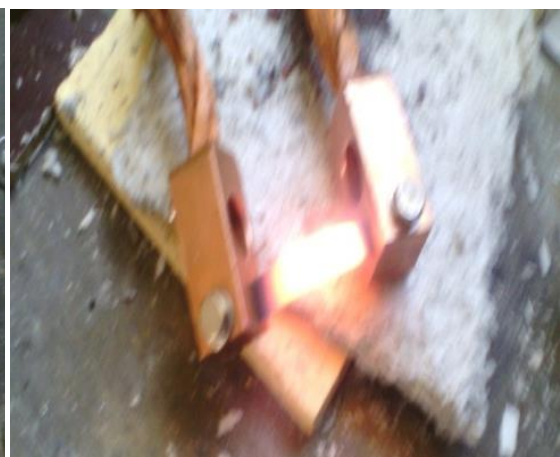

б)

Рисунок 1 - а) Установка для проведения КТО; б) Процесс контактной термической обработки, стали Х18H15.

Таблица 1

Режимы КТО.

\begin{tabular}{|c|c|c|}
\hline Образец & Время обработки, с & Температура обработки, ${ }^{\mathbf{C}}$ \\
\hline Эталон (без обработки) & - & - \\
\hline I & 10 & 500 \\
\hline II & 20 & 537 \\
\hline III & 30 & 584 \\
\hline
\end{tabular}

После КТО были изготовлены шлифы для микроанализа микроструктур, фотографии микроструктуры приведены на рисунке 2.
При анализе микроструктур установлено, что с увеличением параметров воздействия происходит уменьшения размеров зерна 
Impact Factor ISRA (India) $\quad=\mathbf{1 . 3 4 4}$

Impact Factor ISI (Dubai, UAE) $=\mathbf{0 . 8 2 9}$

based on International Citation Report (ICR)

Impact Factor GIF (Australia) $\quad \mathbf{0} \mathbf{0 . 3 5 6}$
Impact Factor JIF

$=\mathbf{1 . 5 0 0}$

Impact Factor SIS (USA)

$=0.912$

Impact Factor РИНЦ (Russia) $=\mathbf{0 . 1 7 9}$

Impact Factor ESJI (KZ) $\quad=\mathbf{1 . 0 4 2}$
После КТО были произведены механические испытания, включающие в себя измерения микротвердости на приборе ПМТ-3 и испытание на растяжение, на разрывной машине Р200M, результаты которых, после статистической обработки приведены в таблице 2. Графическое изображение результатов приведено на рисунке 3.

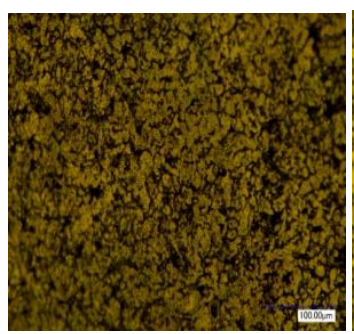

a)

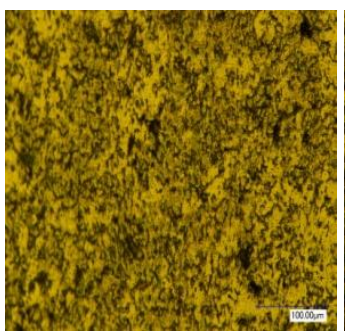

б)

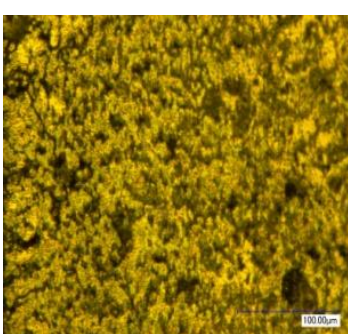

B)

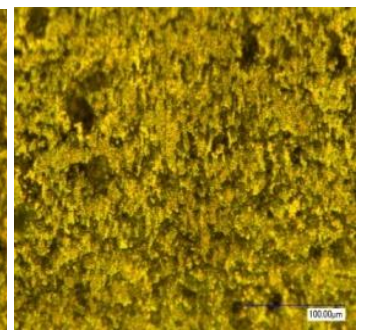

г)

Рисунок 2 - Микроструктура исследуемых образцов стали Х18H15, х700: a) Эталон, б) I, в) II, г) III.

Таблица 2

Результаты измерения микротвердости, после статистической обработки.

\begin{tabular}{|l|r|r|r|r|r|r|}
\hline & \multicolumn{1}{|c|}{$\mathrm{X}$} & \multicolumn{1}{c|}{$(\mathrm{Sx})^{2}$} & \multicolumn{1}{c|}{ Sx } & \multicolumn{1}{|c|}{ Кв } & \multicolumn{1}{|c|}{$\xi$} & \multicolumn{1}{c|}{$\%$} \\
\hline Эталон & 551,15 & 725,57 & 26,93 & 0,048 & 15,62 & 2,84 \\
\hline I & 623,35 & 184,64 & 13,58 & 0,023 & 7,88 & 1,26 \\
\hline II & 714,62 & 822,38 & 28,67 & 0,041 & 16,62 & 2,33 \\
\hline III & 864,40 & 360,27 & 18,98 & 0,022 & 11,02 & 1,27 \\
\hline
\end{tabular}

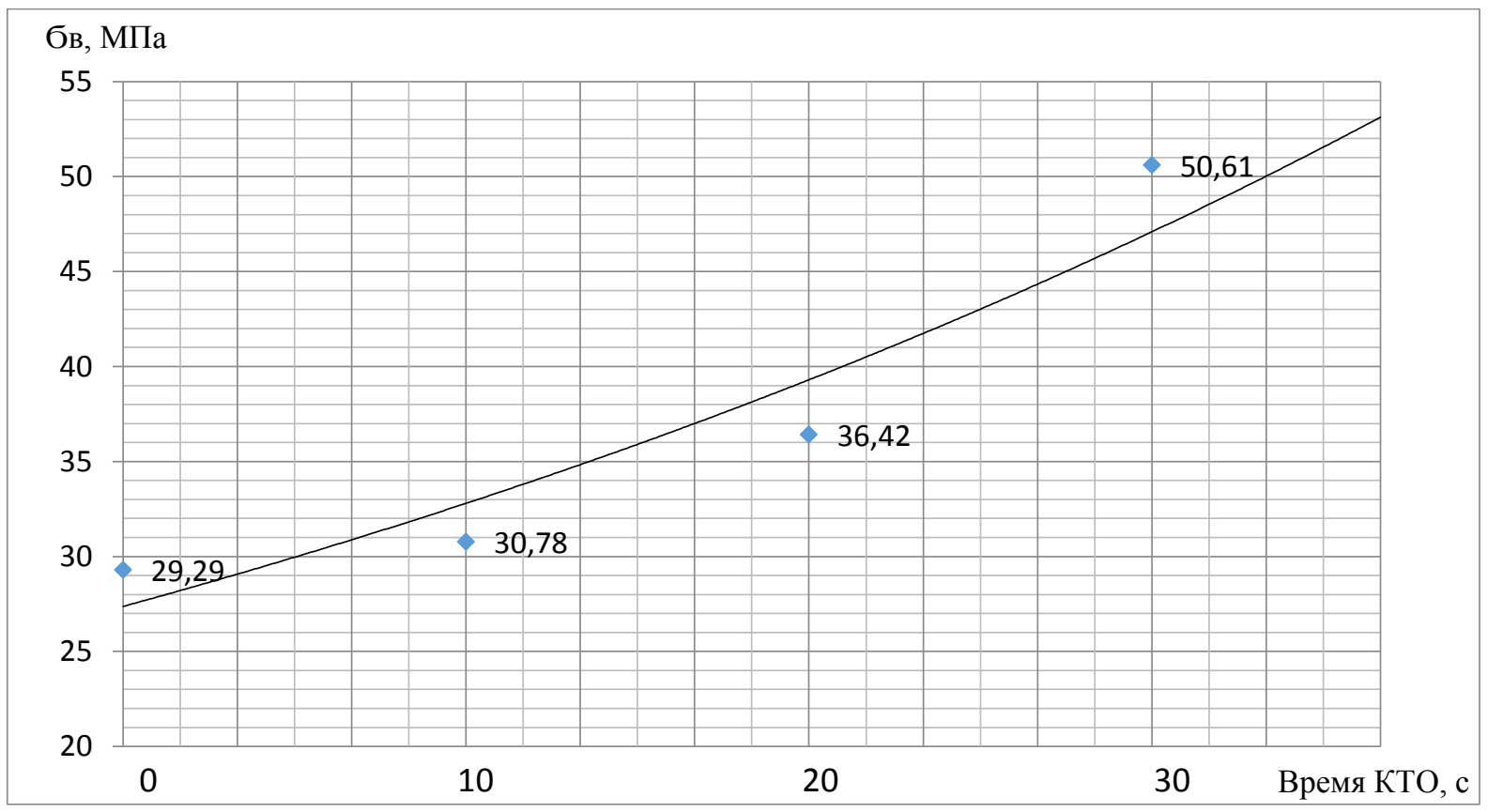

Рисунок 3 - Влияние КТО на предел прочности стали Х18Н15.

ISPC Industry \& Technology Europe, 
В следствии проведенного исследования, выявлена склонность стали Х18Н15 к повышению твердости после КТО, кроме того, предел прочности так же возрастает, с увеличением времени КТО, что может быть обусловлено выделением оксидов, при термической обработке без защитной атмосферы.

\section{References:}

1. Zhuk NP (2006) Kurs teorii korrozii i zashhity metallov./ Uchebnoe posobie. - Moscow: OOO TID «Al'jans», 2006. - $472 \mathrm{p}$.

2. Voskobojnikov VG, etc. (2005) Obshhaja metallurgija - 6-izd., pererab. i dop. - Moscow: IKC «Akademkniga», 2005. - 768 p.

3. Getmanovskij JA, Beljaev ES, Kostromin SV (2014) Issledovanie vlijanija «vodorodnoj bolezni» na mehanicheskie svojstva mednogo prokata // Progressivnye tehnologii i processy [Tekst]: Sbornik nauchnyh statej Mezhdunarodnoj molodezhnoj nauchnoprakticheskoj konferencii (Kursk, 25-26 sentjabrja 2014 g.) - Kursk: Jugo-Zap. gos. un-t, 2014. - V 2-h tomah, T.1.- pp.133-137.

4. Romashev MA, Kostromin SV, Beljaev ES (2014) Issledovanie mikrotverdosti poroshkovyh stalej 10, 15 posle processa lazernoj cementacii // Budushhee nauki-2014 [Tekst]: Sbornik nauchnyh statej Mezhdunarodnoj molodezhnoj nauchnoj konferencii (Kursk, 23-25 aprelja 2014 g.) Kursk: Jugo-Zap. gos. un-t, 2014. - V 3-h tomah, T.3. - pp.158-161.

5. Getmanovskij JA, Romashev MA, Beljaev ES, Gavrilov GN, Kostromin SV (2015) Issledovanie vlijanija kontaktnoj termicheskoj obrabotki na strukturu i svojstva stali H18N15 // Sovremennye problemy biomedicinskoj inzhenerii: sbornik materialov Vserossijskoj molodezhnoj nauchnoj konferencii. (6-8 aprelja 2015 g.) - Moscow: Prondo, 2015. - pp. 93-98.

6. Makhlouf MM, Mould AM, Merchant HD (July 1979) "Sintering of Chemically Preconditioned Tin Powder".Intern. J. Powder Metallurgy and Powder Tech. 15 (3): 231-237.

7. Khan MK (April 1980) "The Importance of Powder Particle Size and Flow Behavior in the Production of P/M Parts for Soft Magnetic Applications". Intern. J. Powder Metallurgy and Powder Tech. 16 (2): 123-130.

8. Jones WD (1960) Fundamental Principles of Powder Metallurgy. London: Edward Arnold Ltd.

9. Todd, Robert H, Allen, Dell K, Alting, Leo (1994) "Manufacturing Processes Reference Guide", 1st Edition, Industrial Press Inc., New York 1994, ISBN0-8311-3049-0.

10. Meyers MA, Wang SL (1988) "An Improved Method for Shock Consolidation of Powders." Acta Metall. Vol. 36 No. 4, pp. 925-936.

11. Vreeland T, Jr, Kasiraj P, Thomas J. Ahrens, Schwartz RB (1983) "Shock Consolidation of Poders--Theory and Experiment. Proc. 1983 Materials Research Society Meeting.

12. Marius Vassiliou, Rhodes CG, Mitchell MR, Graves JA (1989) "Metastable Microstructure in Dynamically Consolidated g Titanium Aluminide," Scripta Metallurgica 23, 17911794. 